\title{
Dietary supplementation with combined extracts from garlic (Allium sativum), brown seaweed (Undaria pinnatifida), and pinecone (Pinus koraiensis) improves milk production in Holstein cows under heat stress conditions
}

\author{
Jae-Sung Lee', Sukyung Kang ${ }^{2}$, Min-Jeong Kim', Sung-Gu Han², and Hong-Gu Lee ${ }^{1,3, *}$
}

* Corresponding Author: Hong-Gu Lee Tel: +82-2-450-0523, Fax: +82-2-3436-0106,

E-mail: hglee66@konkuk.ac.kr

${ }^{1}$ Department of Animal Science and Technology, Sanghuh College of Life Sciences, Konkuk University, Seoul 05029, Korea

2 Department of Food Science and Biotechnology of Animal Resources, Sanghuh College of Life Sciences, Konkuk University, Seoul 05029, Korea

${ }^{3}$ Team of An Educational Program for Specialists in Global Animal Science, Brain Korea 21 Plus Project, Sanghuh College of Life Sciences, Konkuk University, Seoul 05029, Korea

ORCID

Jae-Sung Lee

https://orcid.org/0000-0001-8940-9862 Sukyung Kang

https://orcid.org/0000-0001-6258-3289

Min-Jeong Kim

https://orcid.org/0000-0002-0254-4293

Sung-Gu Han

https://orcid.org/0000-0002-1485-861X Hong-Gu Lee

https://orcid.org/0000-0002-0679-5663

Submitted Jul 2, 2019; Revised Aug 4, 2019; Accepted Nov 11, 2019
Objective: This study was conducted to examine the effects of a mixture of pinecone oil, garlic, and brown seaweed extracts (PGBE) on milk production traits as well as physiological and ethological parameters in Holstein cows during the summer season (24 May to 03 July 2015, Korea).

Methods: Among the extract combinations tested, we found that the level of 2,2'-azino-bis (3-ethylberzothiazoline-6-sulphonic acid) cation radical scavenging activity of the $0.16 \%$ PBGE complex at ratio of 1:1:1 (vol/vol) was comparable to that of the control (ascorbic acid; $1 \mathrm{mg} / \mathrm{mL}$ ). Additionally, the PBGE complex reduced lipopolysaccharide-induced COX2 expression in bovine mammary epithelial cells. Based on these findings, 40 lactating Holstein cows were used to measure the effects of PBGE complex at ratio of 1:1:1 (vol/vol) on milk production, immune response, metabolites, and behavior patterns by dividing the cows into two groups fed diets containing PGBE complex $(\mathrm{n}=20 ; 0.016 \% / \mathrm{kg}$ feed dry matter basis) or not containing PGBE complex (control, $\mathrm{n}=20$ ) for $40 \mathrm{~d}$.

Results: Results showed that PGBE complex did not influence milk composition, eating and ear surface temperature patterns, immune response, or metabolic parameters but promoted average milk yield throughout the experimental period. Additionally, a tendency of higher total antioxidant capacity and glutathione in the PGBE group was observed compared to the those in the control. When the temperature-humidity index (THI) exceeded 72 (average $\mathrm{THI}=73.8)$, PGBE complex-fed cows experiencing heat stress showed increased milk yield and a tendency of increased rumination compared to the control.

Conclusion: We suggest that incorporation of a combined mixture of $0.016 \%$ PGBE (1:1:1 ratio, vol/vol) to diet has the potential to improve milk yield and health status of cows under mild to moderate heat stress, denoting that it might be useful as an alternative anti-stressor in the diet of dairy cows under hot conditions.

Keywords: Dairy Cow; Temperature-humidity Index; Heat Stress; Reproductive Trait; Feed Additive

\section{INTRODUCTION}

By the end of the twenty-first century, it is likely that surface air temperatures will increase by $6^{\circ} \mathrm{C}$ across the Korean peninsula [1]. Consequently, there is likely to be an increase in the incidence of heat stress in livestock, which will influence their productivity. The temperature-humidity index (THI), which incorporates the effects of ambient temperature and relative humidity, is widely used as an indicator of the degree of heat stress [2]. Heat stress negatively affects a variety of animal production parameters (e.g., milk quality, feed intake, 
and milk yield). A study by Rhoads et al [3] showed that the dry matter intake (DMI) and milk yield are lower in heatstressed cows than in cows that are kept in a thermoneutral environment. In addition to declines in feed intake and milk yield, significant decreases in milk quality have been reported under heat stress conditions [4]. Several management strategies for heat stress (e.g., provision of shade and cooling systems) have ameliorated some of the negative effects of thermal stress on animal productivity; however, productivity continues to decrease during heat events in summer, particularly in dairy cows.

One approach, dietary supplementation with a variety of natural resource extracts, is expected to alleviate the negative impact of heat events by improving health status and eventually contributing to increases in milk yield in dairy cows. Advances in supplementation with phytogenic or marine extracts as single components have improved the growth performance and health status of domestic animals by promoting appetite, enhancing feed digestibility, and improving immune responses and antioxidant capacity [5-7]. For instance, the compounds in garlic, such as S-allylcysteine, show great antioxidant potential by increasing the activity of several antioxidant enzymes [8,9]. A study by Kim et al [10] showed that the major components of phytonic oil extracted from pinecone are $\gamma$-terpinene, dl-limonene, $2-\beta$-pinene, and isolongifolene, and that the components of pinecone oil have multiple biological properties including antioxidant and suppresion of cortisol. Brown seaweed is rich in a polysaccharide of alginic acid, and it been demonstrated that polysaccharide of fucoidan in brown seaweed shows antitumor, anticancer, and antioxidation effects [11,12]. However, information on supplementation with a mixture of phytogenic and marine extracts and its effects on cow performance and physiological traits is limited. Considering the adverse effects caused by heat events, we speculated that supplementation with the mixture of combined extracts would alleviate heat stress and improve animal performance and productivity. The present study was performed to evaluate the immunomodulatory potency of a mixture of phytogenic extracts (garlic and pinecone) and a marine extract (brown seaweed) using bovine mammary epithelial cells (MAC-T) in vitro. Based on the results of these experiments, we further examined the in vivo effects of a combination of phytogenic and marine extracts on milk production, milk quality, immune status, metabolic profiles, and behavior patterns of dairy cows experiencing heat stress during summer in the Republic of Korea.

\section{MATERIALS AND METHODS}

The current study consisted of two experiments. In Experiment 1, a mixture of pinecone oil, garlic kernel, and brown seaweed midrib extracts (PGBE) was used to determine the optimal combination through analysis of radical scavenging activity using 2,2'-azino-bis (3-ethylberzothiazoline-6-sulphonic acid) (ABTS) and anti-inflammation using MAC-T to determine whether PGBE can be used as a feed additives in dairy cows. Based on the results from Experiment 1, we confirmed the impact of PGBE complex on milk production, milk composition, metabolic profiles, immune status, antioxidative parameters, and behavior patterns in dairy cows experiencing heat stress were evaluated in Experiment 2.

\section{Experiment 1: Screening for immunomodulatory potency of PGBE complex using MAC-T}

Preparation of phytogenic and marine extracts and their mixtures: Extracts of pinecone oil, garlic kernel, and brown seaweed midrib were provided by the Phylus Corporation (Danyang, Korea). Each material-pinecone without pine nuts, garlic kernel, and brown seaweed midrib-was segmented into fragments of 2 to $3 \mathrm{~cm}$ in size, and $100 \mathrm{~g}$ of each was added into a $1 \mathrm{~L}$ flask. These were mixed with $500 \mathrm{~mL}$ distilled water for 1 to $2 \mathrm{~min}$, followed by a distillation process at $100^{\circ} \mathrm{C} \pm 3^{\circ} \mathrm{C}$ for $3 \mathrm{~h}$. Each extract obtained using distillation was dehydrated with sodium sulfate for $24 \mathrm{~h}$, and then collected, sealed, and stored at $4^{\circ} \mathrm{C}$. To prepare the PGBE complex, the aforementioned extracts were mixed in the following combinations: 1:1:1, 2:1:1, 1:2:1, and 1:1:2 (vol/vol). All extractions were serially diluted with Dulbecco's modified eagle's medium (DMEM; Thermo Fisher Scientific Inc., Waltham, MA, USA) supplemented with $1 \%$ heat-inactivated fetal bovine serum (FBS; Gibco, Grand Island, NY, USA), filtered through a 0.22 $\mu \mathrm{m}$ membrane (MN sterilizer PES; Macherey-Nagel GmbH Co., Duren, Germany), and sealed and stored at $4^{\circ} \mathrm{C}$ until their use in the in vitro study.

Antioxidant activity using ABTS cation radical scavenging activity assay: The antioxidant capacity of the PGBE complex was investigated using ABTS cation radical scavenging activity assay, as described by Cai et al [13]. ABTS radical cations generated by reacting 7.2 millimolar $(\mathrm{mM})$ ABTS and $2.6 \mathrm{mM}$ potassium persulfate for $24 \mathrm{~h}$ in a dark room were diluted with phosphate-buffered saline ( $\mathrm{pH} 7.4$ ) so as to give $20 \%$ to $30 \%$ inhibition of the blank absorbance at $734 \mathrm{~nm}$ with a spectrophotometer (Biotek Instruments, Inc., Winooski, VT, USA). Subsequently, $10 \mu \mathrm{L}$ of PGBE complex or L-ascorbic acid was added into $190 \mu \mathrm{L}$ of ABTS solution to get a final PGBE concentration of $0.16 \%$ to $0.01 \%$ (vol/vol) or L-ascorbic acid (1.0, 0.1 and $0.01 \mathrm{mg} / \mathrm{mL}$; Sigma-Aldrich, St. Louis, MO, USA) in a 96-well plate (Thermo Fisher, USA), and reacted for $10 \mathrm{~min}$ in a dark room. The optical density (OD) of the resulting mixture was measured at $734 \mathrm{~nm}$, and radical scavenging activity was calculated using the following formula: 1 - (OD blank OD sample)/OD blank.

Anti-inflammatory activity assessed using western blot analysis: MAC-T cells [14], immortalized bovine MAC-T, were 
cultured in DMEM (Thermo Fisher, USA) medium with $10 \%$ heat-inactivated FBS, 1\% penicillin/streptomycin solution (Gibco, USA), $5 \mu \mathrm{g} / \mathrm{mL}$ bovine insulin (Sigma-Aldrich, USA), and $1 \mu \mathrm{g} / \mathrm{mL}$ progesterone (Sigma-Aldrich, USA) at $37^{\circ} \mathrm{C}$ in a humidified atmosphere of $95 \%$ air and $5 \% \mathrm{CO}_{2}$. After reaching $90 \%$ confluence, cells were synchronized overnight in complete medium containing $1 \%$ heat-inactivated FBS before initiation of cell treatments. No mycoplasma was detected in the cultures.

Anti-inflammatory activity of PGBE was assessed using western blot analysis as described previously [15]. In brief, MAC-T cells $\left(5 \times 10^{5}\right.$ cells $\left./ \mathrm{cm}^{2}\right)$ were grown to confluence and synchronized overnight in 6-well plates (Thermo Fisher, USA). Cells were pretreated at a concentration of $0.16 \%$ PGBE complex (1:1:1 ratio; vol/vol) for $6 \mathrm{~h}$, and exposed to PBS or lipopolysaccharide Escherichia coli O111:B4 (LPS; SigmaAldrich, USA) at a concentration of $1 \mu \mathrm{g} / \mathrm{mL}$ for $12 \mathrm{~h}$. For western blot analysis, $30 \mu \mathrm{g}$ protein per lane from total extracts of each sample was separated using $10 \%$ sodium dodecyl sulfate-polyacrylamide gel electrophoresis (Mini-Protean Tetra Cell; Bio-Rad Laboratories, Inc., Hercules, CA, USA). Blots were exposed to X-ray film (Fujifilm Co., Tokyo, Japan) for $3 \mathrm{~min}$ and then scanned, and the band densities were quantified using ImageJ 1.43 software (National Institutes of Health. http://rsb.info.nih.gov/ij). Band densities were normalized to glyceraldehyde-3-phosphate dehydrogenase signals on the same membrane.

\section{Experiment 2: Effects of a supplemental mixture of} PGBE on milk yield, milk composition, immune status, metabolic profiles, and behavior patterns in dairy cows experiencing heat stress

Cows, housing, experimental design, and treatments: The Animal Experimental Guidelines provided by the Animal Care and Use Committee of Konkuk University approved all procedures involving animals (KU16053), and the experiment was conducted (24 May to 03 July 2015) in Chugju at the University Farm Facility. A total of 40 lactating Holstein-Friesian cows were housed in a feedlot located in a roofed area with open sides and offered total mixed ration (TMR) and concentrated feed with free access to fresh water. Each pen (4 cows/ pen) in the feedlot was equipped with automatic water troughs. Sawdust was used for bedding and refreshed once monthly. At the beginning of the study (24 May, day 0), cows (parity, $2.3 \pm 0.23$; days in milk, $118 \pm 10.2 \mathrm{~d}$; mean \pm standard deviation) averaging $37.4 \pm 1.28 \mathrm{~kg} / \mathrm{d}$ milk yield were equipped with radio-frequency identification (RFID) ear tags (SensOor, Agis Automatisering BV, Harmelen, The Netherlands) and subsequently assigned to two different dietary groups. The total duration of the experiment was $40 \mathrm{~d}$, during which the cows were fed a basal diet (control, $\mathrm{n}=20$ ) or a basal diet supplemented with $0.016 \%$ PGBE complex (PGBE, $\mathrm{n}=20$ ) at 09:00 h. The PGBE complex (pinecone oil, garlic kernel, and brown seaweed midrib extracts at ratio of 1:1:1 [vol/vol]) was premixed with the excipient (60\% rice bran and $40 \%$ corn grit) at a $10 \%$ concentration and it was added to the TMR at a final concentration of $0.016 \%$ by top-dressing for in vivo study. Cows in the control group were fed the same amount of added the excipient (not included PGBE). The ingredients and chemical compositions of the diet are shown in Table 1. The basal diet was formulated to meet or exceed the nutrient requirements of NRC [16].

Temperature-humidity index: Ambient air temperature (AT, $\left.{ }^{\circ} \mathrm{C}\right)$ and relative humidity $(\mathrm{RH}, \%)$ inside the feedlot were recorded every 10 min daily using a self-made device (Korea Electronics Technology Institute, Seongnam, Korea) located at a height of $3 \mathrm{~m}$ from the ground. THI was calculated using the following equation [17]: $\mathrm{THI}=0.8 \times \mathrm{AT}+(\mathrm{RH} \times[\mathrm{AT}-14.4])$ +46.4 .

Milk collection: Cows were milked twice daily (at 03:30 and 15:30 h), with individual milk yields recorded at each milking. Every $10 \mathrm{~d}$, milk samples from two consecutive milking of individual cows were collected into a $50 \mathrm{~mL}$ tube containing bronopol-B2 preservative (D\&F Control System Inc., Dublin, $\mathrm{ON}$, Canada), pooled with same volume ratio, and kept at $4^{\circ} \mathrm{C}$. Subsequently, the aliquot of milk was analyzed for fat, protein, lactose, somatic cell counts, solid-not fat, milk urea nitrogen, acetone, $\beta$-hydroxybutyrate, and casein- $\beta$, using a MilkoScan (CombiFoss FT+500 S/H, Hilleroed, Denmark).

Behavior patterns: Rumination and eating times of individual cows were monitored continuously using a 3 -dimensional accelerometer attached to the RFID ear tag, which was placed in the proximal half of the ear between the two cartilage folds. Raw data transmitted from cows' ear tags were analyzed via an online application (CowManager; Agis Automatisering BV, The Netherlands) provided by the manufacturer, which records time spent ruminating per hour, eating and ear surface temperature per day.

Blood collection: Blood collections were performed on day 0 and 40 of the experiment. Approximately $15 \mathrm{~mL}$ of duplicate blood samples from individual cows were collected from the jugular vein $4 \mathrm{~h}$ after feeding (at 09:00 h). One aliquot of blood sample was collected in serum separator tubes (Serum Clot Activator, Greiner Bio One GmbH, Kremsmunster, Austria), and the samples were allowed to clot for $30 \mathrm{~min}$ at room temperature and stored in the refrigerator overnight. Subsequently, serum was obtained by centrifugation at $1,300 \times g$ for $30 \mathrm{~min}$ at $4^{\circ} \mathrm{C}$ and used to determine the metabolic profile (blood urea nitrogen, albumin, glucose, non-esterified fatty acids, triglyceride, gamma-glutamyl transpeptidase, and creatine) and antioxidative parameters (total antioxidant capacity [TAC], erythrocyte glutathione [GSH], and thiobarbituric acid reactive substances) using a Toshiba Accute Biochemical Analyzer-TBA-40FR (Toshiba Medical Instruments, Tochigi- 
Table 1. Ingredient and chemical composition of the experimental diets used in Experiment 2

\begin{tabular}{|c|c|c|c|}
\hline Items & TMR & Concentrates & Excipients \\
\hline \multicolumn{4}{|l|}{ Diet ingredient, $\%$ of DM } \\
\hline Canola seed meal & - & 9.00 & - \\
\hline Coconut kernel meal & - & 6.00 & - \\
\hline Corn & - & 20.00 & - \\
\hline Corn gluten feed & 5.00 & 13.60 & - \\
\hline Dicalcium phospate & - & 0.20 & - \\
\hline Limestone & - & 1.50 & - \\
\hline $\mathrm{MgO}$ & - & 0.20 & - \\
\hline Molasses & 1.50 & 6.00 & - \\
\hline Parm kernel meal & 1.00 & 14.20 & - \\
\hline Salt & - & 0.50 & - \\
\hline Sesame seed meal & - & 2.00 & - \\
\hline Sodium bicarbonate & - & 0.40 & - \\
\hline Soybean meal & 2.00 & 10.00 & - \\
\hline Tallow & - & 2.00 & - \\
\hline Tapioca & - & 3.00 & - \\
\hline Vitamin mineral premix & - & 0.40 & - \\
\hline Wheat middling & - & 11.00 & - \\
\hline Canola seed meal & - & 9.00 & - \\
\hline Alfalfa hay & 6.50 & - & - \\
\hline Beef pulp & 2.50 & - & - \\
\hline Concentrate & 18.00 & - & - \\
\hline Corn flake & 9.00 & - & - \\
\hline Cotton seed & 5.00 & - & - \\
\hline Klein grass hay & 5.00 & - & - \\
\hline Oaten hay & 13.00 & - & - \\
\hline Timothy hay & 2.50 & - & - \\
\hline Rice bran & - & - & 60 \\
\hline Corn grit & - & - & 40 \\
\hline DM of feed $(\mathrm{kg} / \mathrm{d})$ & 25.05 & 2.65 & 0.045 \\
\hline \multicolumn{4}{|c|}{ Chemical composition, kg/d of DM (unless otherwise noted) } \\
\hline Crude protein & 3.14 & 0.52 & 0.005 \\
\hline Ether extract & 0.72 & 0.13 & 0.004 \\
\hline Crude fiber & 3.64 & 0.23 & 0.002 \\
\hline Crude ash & 1.22 & 0.22 & 0.002 \\
\hline NDF & 7.09 & 0.68 & - \\
\hline ADF & 3.52 & 0.29 & - \\
\hline $\mathrm{Ca}$ & 0.16 & 0.03 & $<0.000$ \\
\hline$P$ & 0.09 & 0.02 & $<0.000$ \\
\hline $\mathrm{NE}_{\mathrm{L}}(\mathrm{Mcal} / \mathrm{kg} \text { of DM})^{2)}$ & 2.15 & 2.10 & 2.32 \\
\hline
\end{tabular}

Cows were fed basal diet (control) or basal diet supplemented with $0.016 \%$ PGBE complex (PGBE; DM basis) for $40 \mathrm{~d}$. The basal diet was also used for feeding during the pretrial period.

TMR, total mixed ration; DM, dry matter; NDF, neutral detergent fiber; ADF, acid detergent fiber; NEL, net energy of lactation.

1) Vitamin mineral premix: 1,000,000 IU Vit. A, 100,000 IU Vit. $D_{3}, 25,000 \mathrm{mg}$ Vit. $E$, $150 \mathrm{mg} \mathrm{l}, 150 \mathrm{mg} \mathrm{Co}, 2,500 \mathrm{mg} \mathrm{Cu}, 6,250 \mathrm{mg} \mathrm{Fe}, 16,000 \mathrm{mg} \mathrm{Mn}, 10,000 \mathrm{mg} \mathrm{Zn}$, $150 \mathrm{mg} \mathrm{Se}$.

${ }^{2)} \mathrm{NE}_{\mathrm{L}}$ : Mcal/kg of DM was estimated based on NRC [16].

ken, Japan) and colorimetric procedures with commercially available enzyme-linked immunosorbent assay kits (Abcam plc., Cambridge, UK), respectively, according to the manufacturers' instructions. Another aliquot of blood was collected into $\mathrm{K}_{2}$ ethylenediaminetetraacetic acid-containing vacutainer (BD Vacutainer, Franklin Lakes, NJ, USA) and immediately subjected to hematology using a VetScan HM2 Hematology System (Abaxis Inc., Union City, CA, USA) to evaluate the level of white blood cells, lymphocytes, monocytes, and granulocytes, according to the manufacturers' instructions.

\section{Statistical analysis}

Statistical analyses were conducted using the JMP 5.0 software package (SAS Institute Inc., Cary, NC, USA). A Tukey-Kramer honestly significant difference test was used to compare different dilution rates of PGBE complex against the vehicle alone and the radical scavenging activity of the PGBE complex compared to ascorbic acid in experiment 1 (Table 2). In addition, differences in the following variables compared with initial measurement (day 0 ) in experiment 2 were analyzed using the general linear model procedure of SAS and were determined using a Student's $t$-test: differences in metabolic profiles, hematology, milk yield, milk composition, and anti-oxidative parameters (Tables 3,4). The pen was the experimental unit. Milk yield and behavior patterns (Table 5) were analyzed using the MIXED model with repeated measures analyses. In the mixed model, the random effect was the animal into each pen and the least square means were compared using Tukey. Differences were considered statistically significant and tendency if the probability was less than 0.05 and between 0.05 and 0.1 , respectively. Values obtained from experiment 1 and 2 are expressed as the mean with standard error of mean and mean with standard deviation, respectively.

\section{RESULTS AND DISCUSSION}

\section{Experiment 1: Screening for immunomodulatory potency of the PGBE complex using MAC-T}

The production of excessive reactive oxygen species, which causes oxidative stress and protein oxidation [18], is involved in the pathogenesis of many types of inflammatory disease. Various natural resources from land plants and marine algae with antioxidant effects have been used to treat inflammatory disease. We tested the antioxidant potency of the PGBE complex at various combination rates by estimating its ABTS cation radical scavenging activity (Table 2). All PGBE complexes at dilution rate of $0.16 \%$ showed strong antioxidant effects compared to ascorbic acid $(1.0 \mathrm{mg} / \mathrm{mL})$, but the radical scavenging activity of all PGBE complexes at dilution rates $(0.08 \%$ to $0.01 \%$ ) was weak and even disappeared. PGBE complex containing pinecone, garlic kernel, and brown seaweed midrib extracts $(2: 1: 1 ; \mathrm{vol} / \mathrm{vol})$ was comparable to the other combinations of PGBE (1:1:1 and 1:1:2; vol/vol), with the exception of PGBE combination 1:2:1; vol $/ \mathrm{vol}(\mathrm{p}=0.0478)$. Consequently, $0.16 \%$ PGBE complex $(1: 1: 1 ; \mathrm{vol} / \mathrm{vol})$, as well as consideration of extract costs, was used to evaluate anti-inflammatory ef- 
Table 2. ABTS cation radical scavenging activity of PGBE complex

\begin{tabular}{|c|c|c|c|c|c|c|c|c|}
\hline \multirow{2}{*}{ PGBE ratio ${ }^{1)}$} & \multicolumn{5}{|c|}{ Dilution rate ${ }^{2)}$} & \multicolumn{3}{|c|}{ Ascorbic acid (mg/mL) } \\
\hline & 0.16 & 0.08 & 0.04 & 0.02 & 0.01 & 1.0 & 0.1 & 0.01 \\
\hline 1:1:1 & $84 \pm 11.3^{\mathrm{b}, \mathrm{AB}}$ & $6 \pm 2.8^{d}$ & $3 \pm 9.6^{d}$ & $0.4 \pm 1.0^{d}$ & 0 & $96 \pm 0.7^{a}$ & $54 \pm 5.0^{c}$ & $10 \pm 13.3^{d}$ \\
\hline $2: 1: 1$ & $87 \pm 4.2^{\mathrm{a}, \mathrm{A}}$ & $8 \pm 5.9^{c}$ & $9 \pm 4.6^{c}$ & $0.4 \pm 5.0^{c}$ & 0 & $96 \pm 0.7^{\mathrm{a}}$ & $54 \pm 5.0^{b}$ & $10 \pm 13.3^{c}$ \\
\hline $1: 2: 1$ & $69 \pm 4.7^{\mathrm{b}, \mathrm{B}}$ & 0 & 0 & 0 & 0 & $96 \pm 0.7^{a}$ & $54 \pm 5.0^{b}$ & $10 \pm 13.3^{c}$ \\
\hline $1: 1: 2$ & $85 \pm 0.8^{b, A B}$ & 0 & 0 & 0 & 0 & $96 \pm 0.7^{a}$ & $54 \pm 5.0^{c}$ & $10 \pm 13.3^{d}$ \\
\hline
\end{tabular}

Each value represents the means and standard errors of four replicates.

ABTS, 2,2'-azino-bis (3-ethylberzothiazoline-6-sulphonic acid); PGBE, a mixture of pinecone oil, garlic kernel, and brown seaweed midrib extracts.

1) PGBE ratio represented as a combination ratio of pinecone oil, garlic kernel, and brown seaweed midrib extracts (vol/vol).

${ }^{2)}$ Dilution represented as a ratio of extract and complete medium (\%, vol/vol).

${ }^{a-c}$ Values that differed among diluted groups in a row are significantly different at $p<0.05$ by a Tukey test.

${ }^{A-C}$ Differing values among mixture rates in a column are significantly different at $p<0.05$ by the Tukey test.

fects using MAC-T cells.

MAC-T cells, which are an immortalized epithelial cell line isolated from bovine mammary tissue, provide a useful in vitro model for bovine lactation because they retain a number of biochemical and morphological characteristics typical of bovine primary MAC-T in vivo [14]. Therefore, we suggest that examination of the anti-inflammatory potency of the PGBE complex using MAC-T cells in response to LPS might be useful to understand the similar inflammatory responses of heat stressed dairy cows. COX-2 expression is an indicator of inflammatory responses in a variety of cells, including MAC$\mathrm{T}$ [19]. In order to identify the anti-inflammatory effects of PGBE complex (1:1:1, vol/vol), MAC-T cells were exposed to PGBE complex at concentrations of $0 \%$, and $0.16 \%$ (vol/ $/ \mathrm{vol}$ ) for $6 \mathrm{~h}$, followed by LPS treatment $(0,1 \mu \mathrm{g} / \mathrm{mL})$ for $12 \mathrm{~h}$. Western blot analysis showed that protein expression of COX-2 in MAC-T cells was elevated by LPS $(1 \mu \mathrm{g} / \mathrm{mL})$ as compared to non-LPS treatment (Supplementary Figure S1). Interestingly, we found that pretreatment with $0.16 \%$ PGBE complex ( $1: 1: 1 ; \mathrm{vol} / \mathrm{vol})$ attenuated LPS-induced COX-2 expression in MAC-T cells.

Taken together, these in vitro trials suggest that the combination of PGBE at 1:1:1 ( $\mathrm{vol} / \mathrm{vol}$ ) had the strongest antioxidative potency and anti-inflammatory effects by suppressing COX2 expression in MAC-T cells under LPS stimulation.

\section{Experiment 2: Effects of a supplemental dietary mixture of PGBE on milk yield, milk composition, immune status, metabolic profiles, and behavior patterns in dairy cows experiencing heat stress}

Based on the results of Experiment 1 and data previously described by Kim et al [10], we further examined the effects of supplemental dietary $0.016 \%$ PGBE complex (1:1:1, vol/ vol) on milk yield, milk composition, immune status, met-

Table 3. Effects of PGBE complex on milk yield and composition in dairy cows

\begin{tabular}{|c|c|c|c|c|}
\hline \multirow{2}{*}{ Items } & \multicolumn{2}{|c|}{ Control } & \multicolumn{2}{|c|}{$\mathrm{PGBE}^{1)}$} \\
\hline & D 0 & D 1-40 & D 0 & D 1-40 \\
\hline Milk yield (kg/d) & $37.9 \pm 1.85$ & $37.6 \pm 0.12$ & $36.8 \pm 1.85$ & $39.0 \pm 0.03^{*}$ \\
\hline Feed intake (kg of DM/d) & $27.5 \pm 2.41$ & $27.7 \pm 1.43$ & $27.7 \pm 1.15$ & $27.6 \pm 2.05$ \\
\hline TMR & $25.0 \pm 1.21$ & $25.1 \pm 0.95$ & $25.0 \pm 0.66$ & $25.1 \pm 1.34$ \\
\hline Concentrate & $2.6 \pm 0.12$ & $2.6 \pm 0.42$ & $2.6 \pm 0.88$ & $2.6 \pm 0.57$ \\
\hline \multicolumn{5}{|l|}{ Milk composition } \\
\hline Fat (\%) & $4.07 \pm 0.513$ & $4.00 \pm 0.606$ & $4.15 \pm 0.452$ & $4.04 \pm 0.659$ \\
\hline Protein (\%) & $3.19 \pm 0.201$ & $3.16 \pm 0.217$ & $3.23 \pm 0.280$ & $3.24 \pm 0.286$ \\
\hline Lactose $(\%)$ & $4.78 \pm 0.174$ & $4.78 \pm 0.187$ & $4.80 \pm 0.105$ & $4.84 \pm 0.135$ \\
\hline SNF $(\%)$ & $8.54 \pm 0.244$ & $8.59 \pm 0.271$ & $8.57 \pm 0.304$ & $8.70 \pm 0.292$ \\
\hline $\operatorname{SCC}(\times 1,000 / \mathrm{mL})$ & $150.5 \pm 215.43$ & $158.5 \pm 433.76$ & $83.1 \pm 134.52$ & $104.3 \pm 193.9$ \\
\hline MUN (mg/dL) & $18.8 \pm 2.80$ & $17.5 \pm 2.900$ & $18.9 \pm 3.36$ & $17.8 \pm 2.65$ \\
\hline Acetone (mM) & $0.08 \pm 0.038$ & $0.10 \pm 0.048$ & $0.08 \pm 0.024$ & $0.09 \pm 0.041$ \\
\hline $\mathrm{BHBA}(\mathrm{mM})$ & $0.02 \pm 0.017$ & $0.02 \pm 0.019$ & $0.02 \pm 0.020$ & $0.02 \pm 0.017$ \\
\hline Casein- $\beta(\%)$ & $2.34 \pm 0.167$ & $2.35 \pm 0.185$ & $2.38 \pm 0.225$ & $2.42 \pm 0.234$ \\
\hline
\end{tabular}

Values represent the means plus standard deviation of 20 individual dairy cows.

PGBE, a mixture of pinecone oil, garlic kernel, and brown seaweed midrib extracts; TMR, total mixed ration; SNF, solids-not fat; SCC, somatic cell count; MUN, milk urea nitrogen; BHBA, $\beta$-hydroxybutyrate.

1) PGBE: mixture of pinecone oil, garlic kernel, and brown seaweed midrib extracts at ratio of 1:1:1 (vol/vol).

* Indicates a significant difference compared to the zero day at $p<0.05$. 
Table 4. Effects of PGBE complex on blood traits in dairy cows

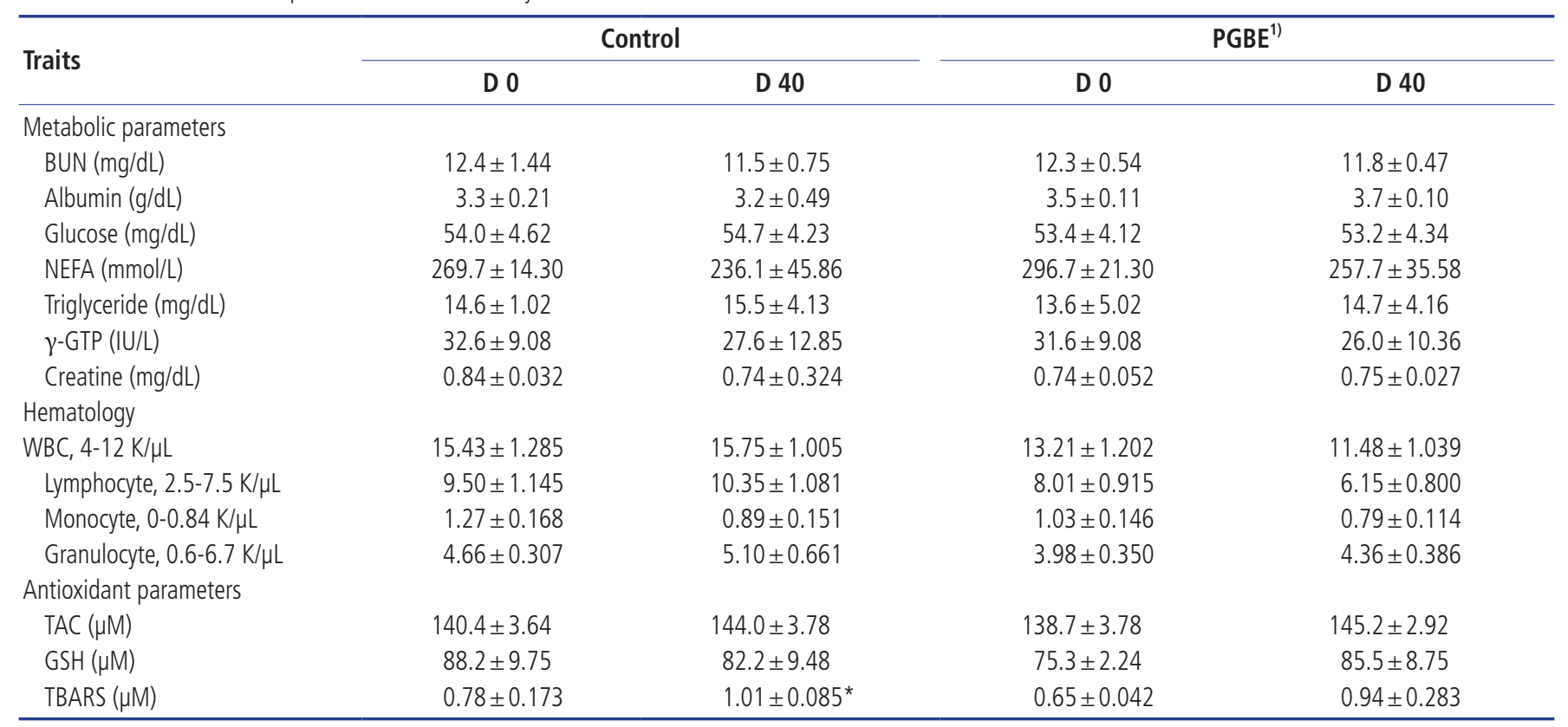

Values represent the means and standard deviation of 20 individual dairy cows.

PGBE, a mixture of pinecone oil, garlic kernel, and brown seaweed midrib extracts; BUN, blood urea nitrogen; NEFA, non-esterified fatty acids; $\gamma$-GTP, gamma-glutamyl transpeptidase; WBC, white blood cells; TAC, total antioxidant capacity; GSH, glutathione; TBARS, thiobarbituric acid reactive substances.

1) PGBE: mixture of pinecone oil, garlic kernel, and brown seaweed midrib extracts at ratio of 1:1:1 (vol/vol).

* Indicates a significant difference compared to value at the initial day (D 0) at $p<0.05$.

abolic profiles, and behavior patterns in dairy cows during heat events in the summer period compared to those of the basal diet to evaluate whether PBGE complex has potential to improve milk production.

Table 5. Effects of PGBE complex on milk yield, and behavior patterns in dairy cows based on the average temperature-humidity index

\begin{tabular}{|c|c|c|c|c|c|c|c|}
\hline \multirow{2}{*}{ Items } & \multicolumn{2}{|c|}{ Control } & \multicolumn{2}{|c|}{$\mathrm{PGBE}^{1)}$} & \multicolumn{3}{|c|}{$p$ value } \\
\hline & 65.6 & 73.8 & 65.6 & 73.8 & Diet (D) & THI (T) & $D \times T$ \\
\hline Initial & $37.9 \pm 1.85$ & - & $36.8 \pm 1.85$ & - & & & \\
\hline Experiment & $38.2 \pm 1.00$ & $37.5 \pm 1.70$ & $39.0 \pm 0.99$ & $38.9 \pm 0.27$ & & & \\
\hline Rumination (\%) & - & - & - & - & & & \\
\hline Initial & $40.8 \pm 0.97$ & - & $38.5 \pm 1.39$ & - & & & \\
\hline Experiment & $39.5 \pm 0.01$ & $38.6 \pm 0.73$ & $40.9 \pm 1.21$ & $39.3 \pm 0.90$ & & & \\
\hline Increment & $-1.3 \pm 0.74$ & $-2.2 \pm 0.64$ & $+2.4 \pm 1.40$ & $+0.8 \pm 1.09$ & 0.7619 & 0.8577 & 0.7207 \\
\hline \multicolumn{8}{|l|}{ Eating (\%) } \\
\hline Initial & $31.7 \pm 0.21$ & - & $31.4 \pm 0.25$ & - & & & \\
\hline Experiment & $29.2 \pm 0.33$ & $32.8 \pm 0.27$ & $29.0 \pm 0.30$ & $32.2 \pm 0.16$ & & & \\
\hline Increment & $-2.5 \pm 0.24$ & $+1.0 \pm 0.23$ & $-3.6 \pm 1.59$ & $-0.9 \pm 1.71$ & 0.3202 & $<0.0001$ & 0.7734 \\
\hline
\end{tabular}

Values represent the means and standard deviation of 20 individual dairy cows.

PGBE, a mixture of pinecone oil, garlic kernel, and brown seaweed midrib extracts; $\mathrm{TH}_{\text {avgr }}$ average temperature-humidity index.

1) PGBE: mixture of pinecone oil, garlic kernel, and brown seaweed midrib extracts at ratio of 1:1:1 (vol/vol).

${ }^{2)}$ Increment: values of experiment vs initial.

a,b means in the same row with different superscripts differ $(p<0.05)$. 
Although there was no significant difference in milk composition and feed intake between the control and $0.016 \%$ PGBE-treated groups during the whole experimental period, the PBGE mixture showed increased milk yield for 40 days as compared to the control group ( $\mathrm{p}<0.05)$ (Table 3$)$. Comparing our observation, a study by $\mathrm{Oh}$ et al [20] showed that milk composition and blood chemistry were not affected by treatment with $2 \mathrm{~g}$ per cow of garlic extract for $9 \mathrm{~d}$. DMI tended to be lower for the garlic treatment, which increased feed efficiency but slightly decreased milk yield. A study by Yang et al [21] investigated the effects of garlic ( $5 \mathrm{~g}$ per cow) and juniper berry ( 2 g per cow) essential oils on ruminal fermentation and on the site and extent of digestion in lactating cows, and reported that milk yield did not change. A prior study showed that incorporation of $0.016 \%$ pinecone oil into basal diet did not have a large influence on milk yield or metabolic and hematological parameters in lactating Holstein cows [10]. A study by Hong et al [5] found that feeding dietary brown seaweed byproducts at $2 \%$ and $4 \%$ for 12 months did not affect DMI, milk yield, or milk composition in Holstein cows. In addition, Benchaar et al [22] observed no changes in milk yield or milk composition in cows supplemented with $2 \mathrm{~g}$ per day or $750 \mathrm{mg}$ per day of a commercial mixture of essential oil compounds, reporting that milk protein and milk lactose content, as well as their yields, were not affected by the treatment. Similarly, milk efficiency, presented either as $\mathrm{kg}$ of milk or as fat-corrected milk per $\mathrm{kg}$ of DMI, did not differ among the groups. Although there was no observed improvement in milk composition following supplementation with the combined mixture of phytogenic extracts (garlic and pinecone) and marine extract (brown seaweed) in the current study, we suggest that supplementation with $0.016 \%$ PGBE at 1:1:1 (vol/vol) in basal diet was effective for improving the milk yield of lactating cows.

A study by Yun et al [9] showed that a garlic bulb consists of the organosulfur compounds alliin, $\gamma$-glutamyl-S-allylcysteine, S-methyl cysteine sulfoxide, S-trans-1-propenylcysteine sulfoxide, S-2-carboxypropylglutathione, and S-allylcysteine. As aforementioned, the compounds in garlic, such as S-allylcysteine, show great antioxidant potential by increasing the activity of several antioxidant enzymes, such as GSH reductase, superoxide dismutase, and g-glutamate cysteine ligase $[8,9]$. A study by Kim et al [10] showed that the major components of phytonic essential oil extracted from pinecone are $\gamma$-terpinene, $\mathrm{dl}$-limonene, $2-\beta$-pinene, and isolongifolene, and that the components of pinecone oil have multiple biological properties including antioxidant and suppression of cortisol. Brown seaweed is rich in a polysaccharide of alginic acid, and it been demonstrated that polysaccharide of fucoidan in brown seaweed shows anticoagulation, antitumor, anticancer, and antioxidation effects $[11,12]$. In the blood traits of cows, we did not observe a significant difference in anti- oxidant ability (TAC and GSH) (Table 4). However, cows in the control group demonstrated significantly increased thiobarbituric acid reactive substances levels for 40 days ( $<<0.05$ ), but cows supplemented with $0.016 \%$ PGBE in basal diet for 40 days showed tendency of an elevation of TAC $(p=0.0751)$ and GSH concentration $(\mathrm{p}=0.0894)$ compared to those on day 0 . Combined with the results in Table 2, we suggest that $0.016 \%$ PGBE complex can scavenge free radicals, causing an antioxidant effect in lactating cows. There were no significant differences in metabolic (blood urea nitrogen, albumin, glucose, non-esterified fatty acid, triglyceride, gamma-glutamyl transpeptidase, and creatine) or hematological (white blood cell, lymphocyte, monocyte, and granulocyte) parameters between the control and $0.016 \%$ PGBE-treated groups.

The THI is a measure that accounts for the combined effects of environmental temperature and relative humidity on cattle to assess the risk of heat stress and prevent major effects. Heat stress causes changes in homeostasis and has been quantified by the measurement of milk production and physiological variables such as body temperature, respiratory rate, and behaviors of cows [23]. According to a study by Gernand et al [24], milk production is not affected by heat stress when mean THI values are under 68 . However, milk production and feed intake begin to decline when beyond THI 68 [24,25]. During the experimental period of 40 days, animals were subjected to mild to moderate stress conditions (temperature, $25.4^{\circ} \mathrm{C} \pm 2.58^{\circ} \mathrm{C}$; humidity, $58.8 \% \pm 14.15 \%$ $[\mathrm{THI}=73.0 \pm 3.05]$ ) in the current study (Supplementary Figure S2). Considering the conditions using THI values, we further evaluated the data to determine the effects on milk yield and behavior patterns (rumination, eating, and ear surface temperature) of cows based on THI values such as stress threshold (temperature, $19.2^{\circ} \mathrm{C} \pm 0.55^{\circ} \mathrm{C}$; humidity, $78.8 \% \pm$ $4.53 \%[\mathrm{THI}=65.6 \pm 1.05]$ ) and mild to moderate stress conditions (temperature, $26.1^{\circ} \mathrm{C} \pm 0.33^{\circ} \mathrm{C}$; humidity, $57.0 \% \pm 2.29 \%$ $[\mathrm{THI}=73.8 \pm 0.38])$ (Table 5). Milk yield between groups was not affected by THI, dietary supplementation, or THI interaction. For milk yield, however, cows experiencing mild to moderate stress $(\mathrm{THI}=73.8)$ in the control group demonstrated tendency of a reduction of milk yield $(\mathrm{p}=0.0781)$ compared with cows under the stress threshold $(\mathrm{THI}=65.6)$. By contrast, when the THI value exceeded 72 (average THI $=73.8$ ), the milk yield in $0.016 \%$ PGBE-treated group was greater as compared to that in the control group ( $\mathrm{p}<0.05)$. Moreover, we observed a tendency of increase in milk yield of cows in the PGBE-treated group as compared to the control group under stress threshold conditions $(p=0.0897)$, suggesting that incorporation of $0.016 \%$ PGBE into the diet improved the milk yield as compared to non-treatment (control) under the stress threshold and even in mild to moderate stress conditions. Rumination is reduced in cows experiencing heat stress [26]. A study by Moallem et al [26] reported 
that the primary negative effect of THI is depression of rumination time, which subsequently leads to a reduction in DMI, followed by decreased milk yield. In the current study, the mild to moderate stress $(\mathrm{THI}=73.8)$ led to a lower percentage of rumination time of cows in the control group compared to the initial period (control $=-2.2 \%$ ). There was no difference in the percentage of rumination time of cows in the PGBE-treated groups according to THI value. When THI was 73.8 , the rumination time of cows in the $0.016 \%$ PGBE-treated group showed a tendency of an elevation compared to that in the control group (control $=-2.2 \%$ vs $0.016 \%$ $\mathrm{PGBE}=0.8 \%, \mathrm{p}=0.0914)$. In the increment, all cows showed a decline in eating and ear surface temperature as THI increased compared to the initial period. Cow behavior studies have shown that cows suffering heat stress eat more frequent, smaller meals and, to increase the surface area available for dissipating body temperature, stand for a longer time and pant as ambient temperature increases [27]. Chewing and rumination might be impaired by panting in heat-stressed cows, particularly during the daytime. Despite a reduction in rumination in the control group, increased rumination of cows in the PGBE-treated group during the mild to moderate stress period was observed in the current study. We can hypothesize that cows supplemented with $0.016 \%$ PGBE might prevent deterioration of depression of rumination time, which subsequently leads to a reduction in DMI and milk yield, when THI was increased

In conclusion, the lactating dairy cows used in this study suffered mild to moderate heat stress throughout the experimental period $(\mathrm{THI}=73.0)$. The milk production of cows experiencing heat stress in this trial showed an increase with supplementation of $0.016 \%$ PGBE complex in the diet. Besides showing antioxidant potency and anti-inflammatory ability, the PGBE complex (1:1:1 ratio, vol/vol), as shown in the aforementioned results in Table 2 and Supplementary Figure S1, prevented a decrease in the milk yield of cows during some periods of the trial ( $\mathrm{THI}=73.8)$. In particular, rumination time was negatively affected by hot conditions, but cows supplemented with PGBE complex exhibited increased rumination compared to the control. Our results suggest that incorporation of a combined mixture of PGBE to diet has the potential to improve milk yield and health status of cows under mild to moderate heat stress. Therefore, $0.016 \%$ PGBE (1:1:1 ratio, $\mathrm{vol} / \mathrm{vol}$ ) might be useful as an alternative anti-stressor in the diet of lactating dairy cows under hot conditions.

\section{CONFLICT OF INTEREST}

We certify that there is no conflict of interest with any financial organization regarding the material discussed in the manuscript.

\section{ACKNOWLEDGMENTS}

This work was supported by "Cooperative Research Program for Agriculture Science and Technology Development (Project No. PJ013446)" Rural Development Administration, Republic of Korea.

\section{REFERENCES}

1. Boo KO, Kwon WT, Oh JH, Baek HJ. Response of global warming on regional climate change over Korea: An experiment with the MM5 model. Geophys Res Lett 2004;31:L21206. https://doi.org/10.1029/2004GL021171

2. Hubbard KG, Stooksbury DE, Hahn GL, Mader TL. A climatological perspective on feedlot cattle performance and mortality related to the temperature-humidity index. J Prod Agric 1999;12:650-3. http://dx.doi.org/10.2134/jpa1999.0650

3. Rhoads ML, Rhoads RP, VanBaale MJ, et al. Effects of heat stress and plane of nutrition on lactating Holstein cows: I. Production, metabolism, and aspects of circulating somatotropin. J Dairy Sci 2009;92:1986-97. https://doi.org/10.3168/ jds.2008-1641

4. Rodriquez LA, Mekonnen G, Wilcox CJ, Martin FG, Krienke WA. Effects of relative humidity, maximum and minimum temperature, pregnancy, and stage of lactation on milk composition and yield. J Dairy Sci 1985;68:973-8. https://doi.org/10. 3168/jds.S0022-0302(85)80917-6

5. Hong ZS, Kim EJ, Jin YC, Lee JS, Choi YJ, Lee HG. Effects of supplementing brown seaweed by-products in the diet of Holstein cows during transition on ruminal fermentation, growth performance and endocrine responses. Asian-Australas J Anim Sci 2015;28:1296-302. https://doi.org/10.5713/ajas.15.0235

6. Lee JS, Kim MJ, Park SH, et al. Effects of dietary mixture of garlic (Allium sativum), coriander (Coriandrum sativum) and probiotics on immune responses and caecal counts in young laying hens. J Anim Physiol Anim Nutr (Berl) 2017;101:e12232. https://doi.org/10.1111/jpn.12573

7. Abou-Elkhair R, Ahmed HA, Selim S. Effects of black pepper (Piper Nigrum), turmeric powder (Curcuma Longa) and coriander seeds (Coriandrum Sativum) and their combinations as feed additives on growth performance, carcass traits, some blood parameters and humoral immune response of broiler chickens. Asian-Australas J Anim Sci 2014;27:847-54. https:// doi.org/10.5713/ajas.2013.13644

8. Tsai CW, Chen HW, Sheen LY, Lii CK. Garlic: Health benefits and actions. Biomedicine 2012;2:17-29. https://doi.org/10. 1016/j.biomed.2011.12.002

9. Yun HM, Bana JO, Park KR, et al. Potential therapeutic effects of functionally active compounds isolated from garlic. Pharmacol Ther 2014;142:183-95. https://doi.org/10.1016/j.phar mthera.2013.12.005

10. Kim MJ, Jung US, Jeon SW, et al. Improvement of milk fatty 
acid composition for production of functional milk by dietary phytoncide oil extracted from discarded pine nut cones (Pinus koraiensis) in holstein dairy cows. Asian-Australas J Anim Sci 2016;29:1734-41. https://doi.org/10.5713/ajas.16.0281

11. Fernandez-Panchon MS, Villano D, Troncoso AM, GarciaParrilla MC. Antioxidant activity of phenolic compounds: From in vitro results to in vivo evidence. Crit Rev Food Sci Nutr 2008;48:649-71. https://doi.org/10.1080/104083907017 61845

12. Atashrazm F, Lowenthal RM, Woods GM, Holloway AF, Dickinson JL. Fucoidan and cancer: a multifunctional molecule with anti-tumor potential. Mar Drugs 2015;13:2327-46. https:// doi.org/10.3390/md13042327

13. Cai YZ, Luo Q, Sun M, Corke H. Antioxidant activity and phenolic compounds of 112 traditional Chinese medicinal plants associated with anticancer. Life Sci 2004;74:2157-84. https://doi.org/10.1016/j.lfs.2003.09.047

14. Huynh HT, Robitaille G, Turner JD. Establishment of bovine mammary epithelial cells (MAC-T): an in vitro model for bovine lactation. Exp Cell Res 1991;197:191-9. https:/doi. org/10.1016/0014-4827(91)90422-Q

15. Kang S, Lee JS, Lee HC, et al. Phytoncide extracted from pinecone decreases LPS-induced inflammatory responses in bovine mammary epithelial cells. J Microbiol Biotechnol 2016;26: 579-87. http://dx.doi.org/10.4014/jmb.1510.10070

16. National Research Council. Nutrient requirements of dairy cattle. 7th rev. ed. Washington, DC, USA: National Academies Press; 2001. https://doi.org/10.17226/9825

17. Thom EC. The discomfort index. Weatherwise 1959;12:57-61. https://doi.org/10.1080/00431672.1959.9926960

18. Berlett BS, Stadtman ER. Protein oxidation in aging, disease, and oxidative stress. J Biol Chem 1997;272:20313-6. https:// doi.org/10.1074/jbc.272.33.20313

19. Kim HN, Kim DH, Kim EH, et al. Sulforaphane inhibits phorbol ester-stimulated IKK-NF-kappaB signaling and COX-2 expression in human mammary epithelial cells by targeting NF-kappaB activating kinase and ERK. Cancer Lett 2014;351: 41-9. https://doi.org/10.1016/j.canlet.2014.03.037

20.Oh J, Hristov AN, Lee C, et al. Immune and production responses of dairy cows to postruminal supplementation with phytonutrients. J Dairy Sci 2013;96:7830-43. https:/doi.org/ 10.3168/jds.2013-7089

21. Yang WZ, Benchaar C, Ametaj BN, Chaves AV, He ML, McAllister TA. Effects of garlic and juniper berry essential oils on ruminal fermentation and on the site and extent of digestion in lactating cows. J Dairy Sci 2007;90:5671-81. https://doi.org/ 10.3168/jds.2007-0369

22. Benchaar C, Petit HV, Berthiaume R, Whyte TD, Chouinard PY. Effects of addition of essential oils and monensin premix on digestion, ruminal fermentation, milk production, and milk composition in dairy cows. J Dairy Sci 2006;89:435264. https://doi.org/10.3168/jds.S0022-0302(06)72482-1

23.Polsky L, von Keyserlingk MAG. Invited review: Effects of heat stress on dairy cattle welfare. J Dairy Sci 2017;100:864557. https://doi.org/10.3168/jds.2017-12651

24. Gernand E, König S, Kipp C. Influence of on-farm measurements for heat stress indicators on dairy cow productivity, female fertility, and health. J Dairy Sci 2019;102:6660-71. https:// doi.org/10.3168/jds.2018-16011

25. Johnson HD. Environmental management of cattle to minimize the stress of climate changes. Int J Biometeorol 1980;24 (Suppl 7):65-78.

26. Moallem U, Altmark G, Lehrer H, Arieli A. Performance of high-yielding dairy cows supplemented with fat or concentrate under hot and humid climates. J Dairy Sci 2010;93:3192-202. https://doi.org/10.3168/jds.2009-2979

27. Frazzi E, Calamari L, Calegari F, Stefanini L. Behavior of dairy cows with different barn cooling systems. Trans ASAE 2000; 43:387-94. http://dx.doi.org/10.13031/2013.2716 